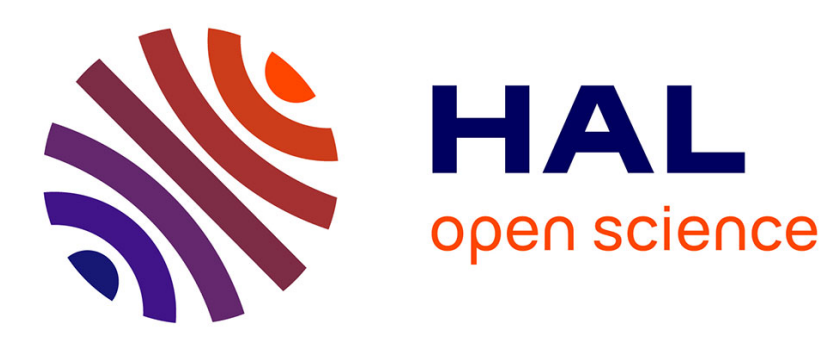

\title{
Education through fiction: acquiring opinion-forming skills in the context of genomics
}

Marie-Christine Knippels, Sabine E. Severiens, Tanja Klop

\section{To cite this version:}

Marie-Christine Knippels, Sabine E. Severiens, Tanja Klop. Education through fiction: acquiring opinion-forming skills in the context of genomics. International Journal of Science Education, 2009, 31 (15), pp.2057-2083. 10.1080/09500690802345888 . hal-00516745

\section{HAL Id: hal-00516745 \\ https://hal.science/hal-00516745}

Submitted on 11 Sep 2010

HAL is a multi-disciplinary open access archive for the deposit and dissemination of scientific research documents, whether they are published or not. The documents may come from teaching and research institutions in France or abroad, or from public or private research centers.
L'archive ouverte pluridisciplinaire HAL, est destinée au dépôt et à la diffusion de documents scientifiques de niveau recherche, publiés ou non, émanant des établissements d'enseignement et de recherche français ou étrangers, des laboratoires publics ou privés. 


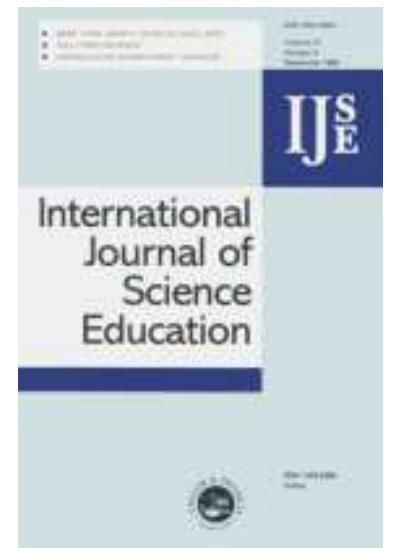

\section{Education through fiction: acquiring opinion-forming skills in the context of genomics}

\begin{tabular}{|r|l|}
\hline Journal: & International Journal of Science Education \\
\hline Manuscript ID: & TSED-2007-0418.R2 \\
\hline Manuscript Type: & Research Paper \\
\hline Keywords: & $\begin{array}{l}\text { biology education, scientific literacy, ethics, secondary school, } \\
\text { quantitative research }\end{array}$ \\
\hline Keywords (user): & Opinion-forming, Genomics, Fiction \\
\hline \multicolumn{2}{|l}{} \\
\hline
\end{tabular}

\section{S ScholaroNE"}




\title{
Education through fiction: acquiring opinion-forming skills in the context of genomics
}

\author{
'Just as physics shocked the $20^{\text {th }}$ century, the life sciences will shake up the world in the $21^{\text {st }}$,
} (Silver, Newsweek, Oct. 2007)

\begin{abstract}
This study examined the outcomes of a newly designed four-lesson science module on opinionforming in the context of genomics in upper secondary education. The lesson plan aims to foster sixteen-year-old students' opinion-forming skills in the context of genomics and to test the effect of the use of fiction in the module. The basic hypothesis tested in this study is whether fiction stimulates students to develop opinions with regard to socio-scientific issues.

A quasi-experimental pre- and post-test design was used, involving two treatment groups and one control group. One of the experimental groups received a science module incorporating movie clips (i.e. the movie group). The other experimental group received the same science module, however, only news report clips were used (i.e. the news report group).

Prior to and after the module, 266 secondary school students completed a questionnaire to test their opinion-forming skills. The results demonstrate that the science module had a significant positive effect on students' opinion-forming skills and that the movie group improved their skills more compared to the news report group.

It may be concluded that the use of fiction, to be more specific movie clips about genomics extracted from feature films, to introduce a socio-scientific issue in the classroom stimulates students to develop their opinion-forming skills.
\end{abstract}




\section{Genomics \& Fiction}

Genomics (i.e. the science of the function, interaction, and products of the total genetic material - genome - in an organism) is a rapidly evolving science with a significant societal impact. The genetic code of a growing number of organisms (including humans) has been identified. Light has been shed on specific genes and gene combinations (mono- and polygenetic) causing disorders (e.g. Huntington's disease, cystic fibrosis, Beta thalassemia), resulting in new methods to diagnose and treat diseases. New techniques and applications of genomic research, such as genetically modified foods, gene therapy, stem cell therapy, and therapeutic cloning, are undergoing rapid development. The well-known example of the first cloned sheep, Dolly, has since been followed up with cloned cats and dogs, as well as contestable reports on cloned humans (e.g. the disputed claim of Italian researcher Severino Antinori that he had successfully implanted a cloned embryo into a woman (e.g. Russell, Marshall, Vogel, Sonneville \& Kondro, 2001; Young \& Carrington, 2002), as well as the rise and fall of 'the king of clones' Hwang Woo-suk from South Korea (e.g. Kennedy, 2006)).

These kinds of news reports on and developments in genomic research impact public opinion and raise mixed feelings, involving values and beliefs, concerns, trust (or the lack thereof), hope and fear. People's opinions, values, knowledge and beliefs in genomic issues are nurtured by different sources, including media, culture, upbringing, personal experiences and education. Societal values and beliefs are also an inherent part of the verbal and visual images we use to communicate: the language we use, the stories we tell, and the pictures and visual technologies that are part of our daily lives (Meulenberg \& De Beaufort, 2006). Public knowledge and notions of genomic research seem to be formed not only by what geneticists and other bio-scientists 
communicate. Science fiction and literature (popular and otherwise), such as novels, comics and films, also play a substantial role (Biesboer, 2003; Meulenberg, De Beaufort \& Van de Vathorst, 2004). People's opinion regarding and fear of cloning, for instance, are often based on the novel and movie 'The Boys From Brazil' in which a scientist creates multiple Hitlers all over the world through cloning technology. Fiction offers images and icons, which over time can become stereotypes or archetypes akin to Dr Jekyll or Dr Frankenstein (Meulenberg et al., 2004). Fictional depictions of scientific theory and experimentation quite probably shape public opinion. Biesboer (2003) draws a similar conclusion: 'Fiction plays an important role in the formation of public opinion about genomics'.

Moreover, science education studies report on the influence of fiction on students' socio-scientific decision-making. The study by Sadler and Zeidler (2004a) unexpectedly demonstrated that students relied on information and predictions provided by the media, literature, and movies with regard to decision-making about genetic engineering dilemmas. The study by Lewis, Driver, Leach, and Wood-Robinson (1997) showed that students used television programmes such as the X-Files, detective series, and science fiction movies as a key source of knowledge for science and genetics.

The significance of fiction on people's opinion is also recognised by several important advisory boards (e.g. the President's Council on Bioethics (2003), the Health Council of the Netherlands (2003)), which recommend further study regarding the use of fiction in genomics education and communication.

This study follows up on this recommendation. We intend to investigate the effect of fiction on secondary students' opinion-forming skills more explicitly. In order to do this, a module was designed, which uses visual aids (i.e. movie and news report clips) that introduce genomic- 
related moral dilemmas in the classroom. The representation of genomics and scientific theories in fiction (movie clips about genomics extracted from feature films) could be a strong medium in introducing a dilemma in the classroom, make students think about facts and fiction, developments and change of insights in science over time, and trigger their imagination and motivation. The basic hypothesis in this study is that fiction encourages students to shape opinions and their opinion-forming skills. To test the effect of fictional representations of genomics on students' opinion-forming skills, compared to the effects of factual representations of that same dilemma, two variants of a science module on opinion-forming in the context of genomics were developed.

\section{Science education and socio-scientific issues}

The development of the two variants of the science module was based on current ideas regarding education with regard to what are known as socio-scientific issues (SSIs). SSIs represent a variety of social dilemmas with conceptual, procedural, or technological associations with science (Fleming, 1986; Kolstø, 2001a; Zeidler, Walker, Ackett, \& Simmons, 2002) and create social debate or controversy (Sadler \& Zeidler, 2005b). A characteristic of SSIs is that they are open-ended, debatable problems, with no definitive correct answers. Philosophers and science educators argue that SSIs inherently involve ethical considerations. The implications and applications of genomics and modern biotechnology are a good example of an SSI, and those genomic-related SSI issues are often moral issues (referring to actions which have the potential to help or harm others or ourselves).

In science education, students' opinion-forming on SSIs is considered an important skill and an essential component of scientific literacy (e.g. Millar \& Osborne, 1998; The American 
Association for the Advancement of Science, 1989; The National Research Council, 1996). The enormous implications of genomics research on society and daily life now and in the near future ask for scientifically literate citizens to be able to make informed and balanced decisions in the context of genomics, both private and public. Promotion of scientific literacy has widely been recognised as a major goal of science education (Driver, Newton, \& Osborne, 2000; Millar \& Osborne, 1998), and the ability to negotiate and resolve SSIs is considered an essential component.

The significance of opinion-forming skills with regard to SSIs has also been recognised by the Dutch school system, demonstrated by its inclusion in the school leaving examination requirements (Minister of Education, Culture and Science, 2004). The Dutch examination programme for biology explicitly include that students should be able to formulate an opinion, as well as give arguments for and defend a point of view on the use of biotechnology, prenatal screening, human reproduction techniques (like IVF and AI), and genetic modification. Moreover, students should be able to gain, select and assess the reliability of written, oral and audiovisual information.

The question is how science education can foster negotiating SSIs and help meet these requirements. Research on science education aiming to stimulate opinion-forming with regard to SSIs shows various considerations and educational models, about which we will present a short description. First of all, the ability to recognise key issues in ethical or moral dilemmas is important for reasoned discussion, and the ability to recognise them requires some understanding of the relevant science (Lewis \& Leach, 2006). This is also important since genetics is one of the most difficult topics for students in biology education due to its complex and abstract nature (Knippels, 2002; Knippels, Waarlo \& Boersma, 2005), and the developments in genetic science 
are rapidly evolving, calling on students' information-seeking skills. A second consideration concerns bio-ethicists' claim (e.g. Evans, 2002) that in order to make or develop informed decisions regarding SSIs you need to have considered the moral implications of those decisions (Sadler \& Zeidler, 2004a). Students' moral reasoning abilities can be fostered by encouraging reflection and participation in open-ended discussions of moral issues (Oser, 1986; Solomon, Watson, \& Battistich, 2001; Veugelers, 2000).

Science education literature provides different models and heuristics in socio-scientific decisionmaking and opinion-forming in which these considerations are taken into account, including Ratcliffe (1997), Kortland (1996, 2001) and Keefer (2001, 2003). Keefer (2001, 2003), for instance, defined a model for decision-making in practical contexts using moral care issues, which entails the following phases: 1 . identification of the moral issue at stake; 2 . identification of relevant knowledge and unknown facts about a problem; 3. proposal of a resolution; 4. provision of a justification; 5. consideration of alternative scenarios arguing for different conclusions; 6. identification and evaluation of moral consequences; 7. proposal of alternative resolutions. Mepham (2003) introduced the ethical matrix as an educational resource for students, in which such ethical principles as well-being, autonomy and justice are applied to the different parties involved in the ethical or moral dilemma. Practical guidance of ethical reflection and discussion, also used in academic ethics education in the Netherlands, is offered by the model proposed by Bolt, Verweij, and Van Delden (2005). They described the following five phases (nine steps):

Phase 1: Exploration 1. Which questions are raised by this specific case?

Phase 2: Explication 2. What is the moral question?

3. Which modes of action are evident/ possible at first sight? 
4. What information is missing at this point?

Phase 3: Analysing 5. Who are involved in this moral dilemma?

6. Which arguments are relevant in answering the moral question?

Phase 4: Weighing 7. What is the weight of the arguments of this specific case?

8. Based on this weighing, which modes of action are to be preferred?

Phase 5: Approach 9. What concrete steps (action) have to be undertaken based on this decision?

Comparing the different models and proposed phases uncovers five basic commonalities. In order to arrive at a well-founded opinion about moral issues, students: a) need to be able to recognise and extract the - or a - moral question of the dilemma at hand, b) have to become aware of the arguments and values they and others use, c) should be able to think through the consequences of their decision, d) should be able to find and use the information needed to guide this process, and, finally, e) should be aware of the necessary steps to arrive at a well-founded opinion (i.e. have the metacognitive knowledge). So, forming a well-founded opinion is a complex process comprising conceptual understanding, identification and weighing of values and arguments, and metacognition - i.e. the knowledge of how to do this - (Reiss, 1999; Waarlo, 2003).

\section{The lesson module}

The considerations discussed above and the five commonalities were taken as a starting point in designing the lesson plan on genomic-related opinion-forming. Given their practical nature, the phases proposed by Bolt et al. (2005) - the steps in this model referring to the five commonalities - guided the design. To help students develop their opinion-forming skills, the 
module invites them to become more aware of their way of reasoning, their values, the people involved and different perspectives. Moreover, the module encourages a consideration of the consequences. This is made possible by incorporating reflection and discussion activities at different points and in different ways (individually, small groups and the entire class) in the module.

The relation between learning activities (LA) per lesson, the phases and steps of Bolt et al. (2005) and the five commonalities discussed above (a to e) is depicted in Table 1. The lessons and learning activities are described in the remainder of this section.

[Insert Table 1 about here]

Lesson 1 - Exploration \& explication: recognise the question in the moral dilemma

After a short introduction on the goals and purpose of this science module, the students were shown a movie clip. The movie groups were shown a ten-minute clip from the film 'Gattaca', the news report group a ten-minute clip of a TV documentary on 'donor babies' (www.netwerk.tv, broadcast on 18 January 2006). The essence of both the movie clip and the news report clip is the same: embryo selection for desirable traits. In case of the donor baby, embryos are selected according to genetic compatibility with the diseased sibling and the lack of the genetic abnormality. The Gattaca clip shows how embryos are selected according to all manner of favourable traits. They are genetically engineered in-vitro to be the optimal recombination of their parents' genetic material.

\footnotetext{
${ }^{1}$ Written and directed by Andrew Niccol and starring Ethan Hawke and Uma Thurman, this 1997 science fiction thriller tells the story of a genetically inferior man, who assumes the identity of a superior one in order to pursue his lifelong dream of space travel.
} 
The movie Gattaca takes place in a near-future world where genetic modification has become the foundation of social order. Mankind has developed the genetic modification techniques to a degree that almost perfect children can be brought into this world. Who has 'bad luck' to be born without interference of the geneticist, waits a live of 'invalid', second-class citizens. The clip shown to the students is an episode at the beginning of the film in which the parents (Marie and Antonio) get their first child (Vincent) in the natural way and than decide to get their second child (Anton; 'worthy to carry his fathers' name') by means of the genetic modification techniques. The geneticist informs the parents that he has selected an embryo on all kind of traits, like baldness, obesities etc. Moreover, the clip shows the struggle of young Vincent growing up as an 'invalid'.

Because movie clips are more likely to be appealing to this age group - for example due to clear personalisation - the news report clips were also selected on identifiable characters. The news report clip tells the story of the family Soran. The parents want to help their eleven-year-old son Blend that has a blood disease (Beta thalassemia) by means of a donor baby. This baby can donate stem cells from its umbilical cord in an attempt to rescue Blend. In this documentary we follow Blend, his siblings, and parents in their daily struggle to cope with the disease. Besides, as this procedure is forbidden in the Netherlands, the parents have to cross the boarder to Belgium where the procedure is allowed (but the insurance will not cover the bills). The (moral) dilemma occurring in this story is whether it should be allowed to give birth to a genetically selected child in order to save another human (in this case Blend).

So, both variants address comparable dilemmas, and both clips were narrative in character and similar in terms of the way the dilemma is personalised. 
Learning activity (LA) 1: Some exploring questions were asked to place the movie clip (or news report clip) in context and make sure the students understand what it was about. LA 2: 'Write down your opinion and reflect'. Students wrote down their initial opinion on the dilemma presented in the movie clip. In small groups, students reflected on each others (initial) opinion in silence, writing a reaction to the standpoint of the other group members. After receiving three responses from peers about their opinion, they discussed their viewpoints in the group. LA 3: 'Need for information'. In a class discussion guided by the teacher, initial ideas and opinions were discussed and reflected on, and the need for more detailed, scientific information was raised (e.g. Is everything that you have seen possible? How do these techniques work?).

The goal of lesson 1 was to have students explore and explicate the dilemma at hand individually and in small groups. In this way all students can first make up their mind in silence and then discuss their initial opinions, arguments, and values in the safety of small groups of peers. It is a first orientation on the dilemma (moral question), their opinion, and arguments they and other students hold (Referring to phase 1 and 2 'Exploration' and 'Explication' in Bolt et al. (2005), commonalities A, B, C, (D), Table 1). Moreover, this lesson aims to let students experience by themselves (LA2) or guided by the teachers' class discussion (LA3), that there is a need for more detailed (scientific) information (commonality D, Table 1).

\section{Lesson 2 - Explication: identify relevant knowledge and unknown facts in the dilemma}

As part of a home assignment, students had to look up information and answer questions on one of the following themes: genetic modification, genetic screening, IVF and genomics (expert method). LA 1: In groups of four students, the different 'experts of a theme' exchanged information, explained techniques and concepts (jigsaw method). LA 2: With these new insights 
about techniques, procedures and the state of affairs of genomic research, they reconsidered the dilemma and judged what was/was not possible at this time. LA 3: The teacher reflected with the whole class on the assignment, the new information and insights and the possible consequences for the dilemma.

Lesson 2 focuses on finding, exchanging and using new information in order to understand the range of the dilemma at hand. The identification of relevant knowledge and unknown facts in the dilemma seeks to sharpen the moral question, generate new arguments and insights, shift opinions, and change views on possible consequences of their opinion. (Referring to commonalities A, B, C with a focus on D; Phase 2 'Explicating' in Bolt et al. (2005), Table 1).

Lesson 3 - Analysing \& weighing: examining parties, values and arguments involved

After an assignment on how to formulate an adequate moral question and a text on ethics (values, ethical principals, choices) - (LA 1), students worked individually to formulate the moral question of the dilemma under consideration (i.e. Gattaca clip or donor baby news report), pro and con arguments, weighing of the arguments, and consequences of these arguments for the various people involved in the dilemma (e.g. the child/embryo, parents, scientist and doctors, society) - (LA 2). These assignments were partly completed as homework.

LA 3: 'Class discussion'. The movie clip was shown once more, after which half of the students engaged in a class discussion on the dilemma presented. The remaining half of the class observed the discussion and noted arguments. The observers reflected on the group discussion. Feedback was given on how well students engaged in the discussion (e.g. listened to each other, showed respect for each other), as well as on the quality and diversity of arguments from the different perspectives in the dilemma. LA 4: 'Individual reflection'. After the class discussion, the 
students wrote down their opinion regarding the dilemma (i.e. their response to the moral question) and whether it had changed since the first lesson.

So, with the new information and insights acquired in lesson 2, the focus of lesson 3 was on analysing the dilemma, formulating and weighing arguments in a more structured and more detailed way. Moreover, students had to actively use their arguments, clarify their opinions, and weigh other participant arguments and opinions in a class discussion. The class discussion is a way of founding and exchanging opinions as well as clarifying one's own and others' values. (Referring to phases 2 to 5 of Bolt et al. (2005), commonalities A to D, implicit E; Table 1).

\section{Lesson 4 - Reflection \& new dilemma}

LA 1: 'Reflection'. The teacher reflected with the whole class on the previous three lessons of the module and the steps they had taken in forming a profound opinion regarding the dilemma. The phases proposed by Bolt et al. (2005) were discussed, though the wording was adjusted.

A new genomic dilemma was introduced. The movie group was shown a ten-minute clip of the film 'Multiplicity', the news report group a Fox News TV report on the cloning of cats, called 'Copy cats'. The essence of both the movie clip and the news report clip is the same: reproductive cloning. In the film Multiplicity, the main character is cloned several times in order to reduce the stress of his busy life (as every clone can take over different duties). The Fox News reports on a company in the USA that clones deceased cats for 34,000 dollars, enabling wealthy cat owners to 'get back' their beloved pet. Both clips introduce the same kind of moral dilemma that is whether it should or should not be allowed to clone individuals.

\footnotetext{
${ }^{2}$ Directed by Harold Ramis and starring Michael Keaton, this 1996 science fiction comedy tells the story of a man who never has enough time for the things he wants to do and who is offered the opportunity to have himself duplicated.
} 
LA 2: The students worked on their own to analyse this new genomic dilemma and work through the phases in forming and justifying their opinion, after which they discussed (LA 3) this issue in small groups of two to four students.

In lesson 4 students are asked to explicate the necessary steps to arrive at a well-founded opinion. The goal was to invite them to reflect on the previous three lessons of the module, in which they rehearsed the steps in small phases (guided by the assignments, worksheets and the teacher). Moreover, in this lesson students had to individually apply the steps in forming their opinion in a new dilemma. (Referring to all phases of Bolt et al. (2005) and all five commonalities with a focus on commonality E; Table 1).

\begin{abstract}
Aim of the study
This study aims to find out whether fictional representations stimulate students to develop their opinion about genomics-related SSIs, more than factual representations. In other words, a science module using movie clips will be more stimulating than the same science module using news report clips. However, we also assume that, regardless of the type of clip, the module will be effective in encouraging students to develop their opinion-forming skills.
\end{abstract}

The following two null hypotheses can be formulated:

$\mathrm{H}_{0}$ 1: The lesson module does not help students to improve their opinion-forming skills in the context of genomics.

$\mathrm{H}_{0}$ 2: Similar effects can be expected from the movie variant and the news report variant of the lesson module. 


\section{Method \\ Research design}

A quasi-experimental design was used to test the effect of the newly designed science module on students' opinion-forming skills and the influence of fiction (movie clips) on students' opinionforming. The design comprised two experimental groups - one movie group and one news report group - and a control group (Table 2). The experimental groups were taught the same four opinion-forming lessons in the context of genomics, the only difference being the use of fictional (movie clip) or factual (news report) visual aids to introduce a genomic dilemma. The module was taught by the students' regular biology teachers as part of the standard biology curriculum just after the unit on heredity and DNA. The control group continued with their regular classes. In order to test the effect on opinion-forming skills, the experimental groups are compared to the control group. In order to determine the influence of fictional dilemmas (film clip) versus science dilemmas (factual news report) on students' opinion-forming, the movie and news report groups are compared.

\section{Pilot test}

The development of the science module included a thorough pilot test. In 2006, two test cases were conducted at three secondary schools in the Netherlands, involving a total of 13 biology classes (303 year-11 students between the ages of 15 and 16). During this pilot year, a total of five movie groups and four news report groups were observed during the module. Multiple data sources were used (i.e. pre- and post-test questionnaires, teachers' and students' assessment of the science module, students' worksheets, students' and teachers' interviews, video records of 
class discussions, audio records of small group discussions, and the researchers' observation notes) to evaluate the pilot science module. Based on the outcomes of these multiple data sources the two pilot variants of the module (movie variant and news report variant) were adjusted and fine-tuned. The major adjustments made after the pilot test were:

An assignment on formulating a correct moral question was introduced in lesson 3 (also see section 'The lesson module'). The teachers' interviews, the questions asked by students during the science module (observation notes), and the way students formulated the moral question in the post-test dilemma indicated that more explicit attention should be paid to formulating and extracting a correct moral question. Although, the students expressed in the evaluation that their genomics knowledge had increased after the module, the post-test, teachers' interviews and evaluation showed other wise. Therefore some adjustments were made in lesson 2. Instead of looking up definitions of related genomics concepts and techniques, the expert method ${ }^{3}$ and jigsaw method were introduced to collect and share information about these genomics techniques and concepts more closely and engage students more actively. Moreover, the observation of the somewhat unfocused class discussion (lesson 3) resulted in the decision to add a worksheet. On this worksheet the students could note arguments given in the class discussion per party involved in the dilemma. Using this tool would make it easier for the students and the teacher to keep focusing on the goal of the class discussion. Because the students and teachers felt that the whole

\footnotetext{
${ }^{3}$ The expert and jigsaw method is a specific cooperative learning technique, in which every student is assigned a specific (learning) task. Just as in a jigsaw puzzle, each piece is essential for the completion and full understanding ('peer teaching') of the final product. In our case the class was divided in four groups of 'experts', studying a specific theme: 1) genetic modification, 2) genetic engineering, 3) IVF or 4) genomics. Subsequently, groups of four students were formed with one expert of every theme, exchanging information, explaining techniques and concepts, and solving problems in which the knowledge of all four experts were needed (jigsaw method).
}

URL: http://mc.manuscriptcentral.com/tsed Email: editor_ijse@hotmail.co.uk 15 
class discussion at the end of lesson 3 was a kind of highlight and completion of the first dilemma (lesson 1 to 3 all revolve around one movie or news report clip), lesson 4 with the introduction of a new dilemma (and new clip) felt as an overload at that moment. To prevent this feeling, all teachers advised in the evaluation of the two pilot variants of the module (interviews and questionnaire), to teach lesson 4 after a few weeks. An additional advantage was that it offered a possibility to find out what the students remembered and could apply after a few weeks (rehearsing). In general the teachers advised to implement opinion-forming lessons introduced by movie clips at multiple stages in the science curriculum. In their experience, practicing (opinionforming) skills over longer periods of time generally increases performance, and both students and teachers enjoyed and appreciated the idea of introducing a dilemma by means of a movie (or news report) clip.

The two pilot variants of the module (movie variant and news report variant) were adjusted and fine-tuned according to the points described above. This study reports on the effects of this third version of the module.

\section{Sample}

A total of eleven biology classes (286 year-11 upper secondary school students) from three schools in the Netherlands participated in this study using the final version of the module. However, 15 students were excluded from the dataset because they did not provide all necessary information, and five more students from the experimental groups were excluded because they had missed more than one lesson of the new science module. As a result, the dataset (Table 2) included a total of 266 sixteen-year-old students, 142 girls and 124 boys, with an average age of 15.6 years. 
[Insert Table 2 about here]

\section{Implementation}

Correct or intended implementation of the two variants of the science module was warranted in different ways. Firstly, the teachers were closely involved in the design of the module. Drafts of the teaching and learning materials were discussed with and evaluated by the teachers at various stages. In addition, the teachers also participated in the pilot year of this study, so that they were all well acquainted with the educational unit beforehand. Secondly, a teachers' manual was written with instructions per lesson and per learning activity, which included background information, learning goals and answer sheets.

The study by Levinson and Turner (2001) showed that teaching opinion-forming skills and managing discussion of social issues places severe demands on teachers. This fact was also communicated by the biology teachers who participated in our study. Science teachers often feel they lack the necessary pedagogical skills and confidence to handle controversial issues in the classroom, while humanities teachers feel uncertain about their limited science knowledge base. To address this issue, a workshop on ethics and the facilitation of moral discussions in the classroom was organised for the biology teachers that participated in this study prior to the educational intervention.

Finally, classroom observations of all lessons of the experimental science module were made, and the lessons were evaluated with the teachers. These observations showed that the module was implemented as intended and no significant deviations occurred, apart from the class 
discussion in lesson 3 in which reflecting on personal aspects, like respect each other, or listen to each other, were not expressed that often.

\section{Questionnaire}

Pre- and post-tests were administered to students in the control and experimental groups. Apart from background variables (i.e. age, gender, religion, interest in the science subjects, science grade, and subject combination), students were asked to write down the steps they usually take (or should take) to arrive at a decision or form an opinion in a difficult daily life dilemma. Moreover, students were asked to formulate their opinion on a dilemma regarding prenatal testing in the case of Huntington's disease (Appendix 1).

The pre-test was administered to students after the regular unit on heredity and DNA and just prior to the first lesson of the experimental science module. The post-test questionnaire was completed after the final lesson of the intervention. The control groups completed the post-test during the same period.

\section{Operationalisation of opinion-forming skills}

This study distinguishes between four dependent variables that together measure opinion-forming skills.

- Performance of opinion-forming

- Metacognitive knowledge about opinion-forming

- Number of arguments

- Ability to extract moral questions and issues 
The students' written opinions regarding the 'Huntington's disease dilemma' during the pre- and post-test were coded according to the scheme presented in Table 3.

[Insert Table 3 about here]

The opinion-forming skills performance was measured by the number of steps the students take in their written opinions, according to the nine steps proposed by Bolt et al. (2005). When a step was apparent in the students' written opinions, the number of this phase was coded, and the total steps were counted (see Table 4). An example of this coding is given in Table 5. Correspondingly, the metacognitive knowledge about opinion-forming was coded by the number of steps apparent in the students' written answers to the question, which steps they usually take to arrive at their opinion about a dilemma. An example of this coding is given in Table 6.

[Insert Table 4 about here]

A second researcher independently coded the pre- and post-test transcripts in terms of opinionforming performance with respect to the Huntington's disease dilemma of 72 students (three classes, $27 \%$ ) to test the reliability of the coding scheme: Cohen's kappa is 0.74. Cohen's kappa for coding the metacognitive knowledge on opinion-forming was 0.79 , based on the dual coding of 126 students. Both values indicate good inter-rater reliability.

The number of arguments were counted and coded as either 'in favour of' or 'against' a decision in the dilemma. A code was also applied according to whether students identified the moral issue, formulated the moral question, and, if so, whether this was right or wrong (see also Table 
3 and 5). For instance, a factual question like 'Is it possible to identify Huntington's disease by an amniocentesis?' was coded as 'wrong' because it is not a moral question (i.e. the answer can be looked up).

\section{[Insert Table 5 and Table 6 about here]}

\section{Data analyses}

Covariance analyses were conducted in order to find out which of the groups reveal the largest effects on opinion-forming skills. The three groups were included as independent variables, the pre-test opinion-forming skill as a covariate, and the post-test as the dependent variable. This is the most common way of analysing experimental data (Leike, 1997). Data was analysed by means of the Statistical Package for Social Sciences software, version 13.0 (SPSS).

\section{Results}

Two null hypotheses are formulated for each of the four dependant variables. The first hypothesis addresses the extent to which both variants of the module succeed in stimulating students to develop their opinion-forming skills. The second hypothesis intends to compare the movie variant and the news report variant.

\section{Performance of skill}

Figure 1 shows the scores of the pre- and post-tests regarding actual performance. Immediately apparent is the movie group's relatively high score on the post-test, as well as the comparable scores on pre- and post-test for the other groups. 
Hypothesis 1.1:

The lesson plan does not help students to increase their opinion-forming performance in the context of genomics.

An analysis of variance is performed that compares group 1 (movie) and group 2 (news report) to group 3 (control). The difference between the experimental groups, on the one hand, and the control group, on the other, is statistically significant $(F(1)=6.973, p<0.009)$. This means that hypothesis 1.1 can be rejected. In this result, the pre-test scores were included as a covariate in the analysis. The average post-test scores in the control group differ from the combined movie and news report groups $(\mathrm{M}$ (combined experimental)=3.86, $\mathrm{SD}=1.44$ and $\mathrm{M}(\mathrm{control})=3.47$ $\mathrm{SD}=1.20$ ). This means that on average the module seems to stimulate students to improve their opinion-forming skills to a greater extent.

[Insert Figure 1 about here]

Hypothesis 1.2:

Similar effects can be expected from the movie variant and the news report variant of the lesson plan in helping students to increase their opinion-forming performance.

The movie and news report groups are compared in an analysis of variance in order to respond to this second hypothesis. The average scores on the post-test differ $(F(1)=7.008, p<0.007)$, thereby rejecting hypothesis 1.2 . The movie group post-test score is higher than the news report group 
score $(\mathrm{M}$ (movie)=4.16, $\mathrm{SD}=1.43$ and $\mathrm{M}$ (news report)=3.48, $\mathrm{SD}=1.37)$. The movie group's relatively high post-test score as shown in Figure 1 reveals a statistically significant difference. Apparently, the movie group students improved their opinion-forming skills to a greater extent than the news report group students. In other words, the movie variant of the module has been more successful than the news report variant.

Even though the statistical tests show that the two variants of the module taken together differ from the control group, the figure indicates that it is not so much the news report variant, but the movie variant that impacts opinion-forming skills. A post-hoc analysis comparing the news report and the control group confirms this. The post-test scores of the news report group do not differ from the post-test scores of the control group $(\mathrm{F}(1)=0.73, \mathrm{p}<0.36)$. In other words, it is the movie variant of the module that encourages students to develop a more profound opinion.

\section{Metacognitive knowledge of opinion-forming}

The student's pre- and post-test scores in Figure 2 reflect their metacognitive knowledge on opinion-forming. The scores represent the number of steps they take when asked to describe their opinion-forming process.

\section{Hypothesis 2.1:}

Students in the movie and news report groups score similar on metacognitive knowledge regarding opinion-forming as students in the control groups.

[Insert Figure 2 about here] 
The results show that students in the movie and news report groups indeed score higher on metacognition in the post-test, compared to students in the control groups $(F(1)=32.29, p<0.000)$. We can therefore reject hypothesis 2.1 . The average score on the post-test in the movie and news report groups is $3.81(\mathrm{SD}=1.91)$ and the average score in the control group is $2.47(\mathrm{SD}=1.65)$. In other words, the students in the movie and news report groups present nearly four steps in their description of arriving at an opinion, whereas students in the control groups present only two and a half steps. Apparently, the science module has encouraged students to learn about the process of opinion-forming, which resulted in the ability to describe the underlying steps in opinionforming to a greater extent.

\section{Hypothesis 2.2:}

Similar effects can be expected from students in the movie group and in the news report group on metacognitive knowledge regarding opinion-forming.

As Figure 2 already suggests, the effects on metacognition in the movie and news report groups are comparable. The analysis of variance shows an $\mathrm{F}$ value that is not statistically significant $(\mathrm{F}(1)=0.304, \mathrm{p}<0.538)$. Hypothesis 2.2 cannot be rejected. The average scores are 3.75 $(\mathrm{SD}=2.02)$ in the movie group and $3.89(\mathrm{SD}=1.78)$ in the news report group.

\section{Number of arguments}

The third indicator for opinion-forming skill is the number of arguments students present to form their opinion. The line of reasoning is that on average students with improved opinion-forming skills use more arguments in shaping their opinion (either negative or positive). We again 
conducted two analyses of variance to find out whether students in the experimental and control groups learn to use more arguments.

Hypothesis 3.1:

Students in the movie and news report groups express the same number of arguments as the control group after the module.

The ANOVA results show that the number of arguments given is higher in the movie and news report groups compared to the control group $(F(1)=9.662$, $p<0.002)$, thereby rejecting hypothesis 3.1. However, as can be seen in Figure 3, the differences among the groups are not what we expected. The control group's pre-test score is relatively high compared to the post-test score. This may be due to the control group participants' low level of motivation to write down their arguments in the post-test. Even though, this 'test resistance' does not appear in the other three dependent variables - students in the control group do take writing down the steps they take seriously (metacognition), as well as their opinion (performance of skill) and the moral issue - it may be that substantiating their opinion with a large number of arguments required too much of an effort on the part of the control group students.

[Insert Figure 3 about here]

Hypothesis 3.2:

Students in the movie group and the news report group express similar numbers of arguments. 
As can be seen in Figure 3, the movie group students produce more arguments than the news report group students. The F-test is statistically significant $(F(1)=6.202, p>0.014)$, and we can reject hypothesis 3.2. The movie group students present just under three arguments on average in the post-test $(\mathrm{M}=2.97, \mathrm{SD}=1.89)$, whereas the news report group students present two arguments $(\mathrm{M}=2.14, \mathrm{SD}=1.78)$.

\section{Extracting the moral question}

The fourth dependent variable concerns the extent to which students are able to extract the moral question or the moral issue from the dilemma presented.

Hypothesis 4.1:

Students in the movie and news report groups extract a correct moral question just as often as the students in the control group.

[Insert Figure 4 about here]

The ANOVA results do not show a significant effect when comparing the movie and news report groups to the control group $(\mathrm{F}(1)=0.49, \mathrm{p}<0.824)$. We cannot reject hypothesis 4.1. Apparently, students in both variants of the science module do not learn to extract the dilemma or issue to a greater extent.

Hypothesis 4.2: 
Students in the movie group extract the correct moral question just as often as students in the news report group.

The difference in growth seen in Figure 4 is not statistically significant $(F(1)=0.500, p<0.480)$, so hypothesis 4.2 cannot be rejected. This means that students in the movie group do not learn to distil the moral issues to a greater extent than the students in the news report group. Neither variant of the science module has succeeded in helping students further to indicate the moral issues at stake.

This could mean that the students have already reached an adequate level of this particular aspect of opinion-forming skills. The relatively high scores seem to support this explanation $(\mathrm{M}(\mathrm{movie})=0.70$ to $\mathrm{M}($ news report $)=0.80 ;$ a score 1.0 means that all students extracted a correct moral question or issue).

\section{Conclusion}

In their analyses of fictional representations of genomics-related issues, Meulenberg and De Beaufort (2006) claim that the way scientific theory and experimentation are depicted in fiction influences or even shapes public opinion about genomics. A small number of studies in science education seem to confirm this claim. Sadler and Zeidler (2004a) and Lewis et al. (1997) reported on the effect of fiction on students' socio-scientific decision-making. However, these studies did not focus on fiction, the results reported were merely unexpected side effects. The general importance attached to opinion-forming skills in a scientifically literate society and the possible role of fiction, as expressed in statements of the President's Council on Bioethics (2003) and the Health Council of the Netherlands (2003), are areas for further study. The central goal of 
the present study was to examine the extent to which fictional representations - in more specific terms movie clips about genomics extracted from feature films - stimulate students to develop their opinion about genomic-related SSIs.

From our study, we may conclude that the claim of Meulenberg and De Beaufort seems to hold true. The results show that the movie variant was more successful than the news report variant in encouraging students to develop a more founded opinion regarding moral issues. It turns out that the movie group students use more steps to arrive at their opinion and that they use more arguments in shaping their opinion. So, hypothesis $\mathrm{H}_{0} 2$ has to be rejected. The effects of the movie variant and the news report variant of the lesson module are not similar with regard to the steps they use to arrive at their opinion and the number of arguments.

However, when it comes to extracting a moral question or formulating the moral dilemma, neither the movie group nor the news report group showed improvement. This means that both the movie group and news report group students did not increase their ability to distil a moral question and that the movie group did not extract the correct moral question more frequently than the news report group. This may be due to the already high mean pre-test scores, indicating that a lot of students are already capable of formulating the moral dilemma. Finally, the movie and news report groups performed better than the control group, but equally well on metacognitive knowledge regarding opinion-forming. Apparently, regardless of the type of clips used, the module seems to help learn about the process of opinion-forming. So, hypothesis $\mathrm{H}_{0} 1$ has to be rejected with respect to three measures: steps they use to arrive at their opinion, number of arguments, and metacognitive knowledge, but it cannot be rejected with respect to 'extracting the moral question'. 
In summary, students from both the movie and the news report groups know how to form an opinion better after completing the science module, but the movie group actually uses this knowledge to a greater extent (performance of skill) and uses significantly more pro and con arguments in shaping their opinion with regard to the Huntington's disease dilemma. In general, it may be concluded that the materials used for the movie group stimulated students to develop a more founded opinion, which means they have taken more steps, and used more arguments in forming their opinion.

\section{Discussion and future research}

This study focused on opinion-forming skills measured as the quality of performance in a written dilemma, the metacognitive knowledge about opinion-forming, the number of arguments used, and the ability to extract a moral question with regard to the dilemma. We focused on the effects of these four dependent variables, but did not give any explanations for these effects. It was beyond the scope of this paper to discuss the underlying reasons for change in the movie and news report groups or to examine students' opinion-forming skill in a more qualitative way. In the remainder of this section, we will suggest three lines of research to further explain the observed effects in the present study. The main question in the present study was whether fictional representations had any effect on students' opinion-forming skill. We have shown that the movie variant stimulates students to improve their opinion-forming skill. An explanation for the difference between the two groups could be that students enjoyed the movie clips more, or identified with the characters from the movie clip more, resulting in greater motivation and consequently an increase in opinion-forming skills. However, the clips were selected carefully, in the way that both variants (movie and news report) should address the same or comparable 
dilemma -i.e. 'embryo selection for desirable traits' and 'cloning of individuals'. Moreover, the clips in both variants were narrative and appealing for this age group. For example, in the first news report clip a young (terminally) ill boy and his family were followed in their (emotional en legal) struggle to get a donor baby. Further research would be necessary to find out whether students enjoyed the movie clips more and could therefore focus on students and teachers appreciation (assessment) of the lesson module in general and the movie clips in particular. This research would uncover the underlying reasons for students to improve their skills in the movie variant of the module and offer more information regarding the effective characteristics of science education in this particular field.

Although the impact and necessity of scientific knowledge and the manner in which students use and assess this knowledge are debated in different studies (e.g. Kolstø, 2001b; Lewis \& Leach, 2006; Means \& Voss, (1996); Sadler, 2004b; Sadler \& Zeidler, 2005a), a second explanation for the success of the movie group could be that these students have learned more (i.e. increase in genomics knowledge level) during the module. Although students from both the movie and the news report groups started the module after their regular heredity and DNA lesson (i.e. adequate knowledge levels in all three groups may be assumed) and although lesson two of the new science module focused on information-seeking in the context of genomics, there could be a difference in what students learned in both module variants. A study that tries to disentangle learning about genomics itself and the process of opinion-forming could offer an explanation for the observed effects in the present study and, again, explain the effectiveness of science education in more detail.

Not only shifts in students' knowledge level of genomics would be of interest for future research, the quality and type of arguments used in their opinion-forming could also provide a better 
understanding of the observed effects. Various studies have already focused on argument patterns (e.g. Erduran, Simon \& Osborne, 2004; Jiménez-Aleixandre, Rodríguez \& Duschl, 2000; Zohar \& Nemet, 2002) and type of argumentation patterns (e.g. Sadler and Zeidler, 2005b). Analysing students' arguments according to Toulmin's Argument Pattern (TAP) (Toulmin, 1958) could provide more insight into the quality of students' arguments. Moreover, Sadler and Zeidler (2005b) identified emotive, rational and intuitive informal reasoning patterns of students in genomic-related SSIs. Investigating different types of arguments used and perspectives considered by students in their opinion could give further insight into differences between the movie and news report groups in opinion-forming skills, as well as the quality of the opinion-forming skill.

Apart from these possibilities for future research aimed at explaining the observed effects and provide more insights into the underlying characteristics of effective science education, there are two improvements in the current design that would strengthen the results.

We have shown an increase in opinion-forming skill performance, metacognitive knowledge and number of arguments in the movie group in this study. However, the results are based on only one written dilemma - the Huntington's disease dilemma - posed in the pre- and post-test. If, for example, students are not interested in this dilemma, it may influence the motivation of the students to actually perform the opinion-forming steps during the pre- and post-tests. Asking the students to solve multiple dilemmas would positively contribute to the validity of the results of this study.

Moral reasoning and forming and justifying an opinion in controversial SSIs is a skill (competence) and therefore most likely not something to be learned in a few lessons. Skills 
generally improve when practiced over longer periods of time. For this reason, it cannot be expected that a four-lesson intervention makes students perfect opinion formers in genomicrelated issues. Therefore, the positive results in the movie group after only four lessons are quite encouraging. The question remains, however, whether this effect would still be found in a delayed post-test. Ideally, such a delayed post-test would be completed after a six-month period.

\section{Recommendations for practice}

Firstly, the module should pay more attention to extracting the moral question from a genomicrelated dilemma. As explained above, a majority of the students are already quite capable of distilling a (correct) moral question. However, the module does not seem to help students that are not mastering this aspect of opinion-forming skill yet. Therefore, an updated version of the module should include new learning activities that pay more attention to formulating and extracting a correct moral question from SSIs.

The study showed that the use of fiction (in more specific terms movie clips about genomics extracted from feature films) had a positive effect on students' opinion-forming skills in the context of genomics. It has not yet been demonstrated whether this is due to, for instance, a greater appreciation or motivation, but our second recommendation is to use fiction/science fiction movie clips more often in the science classroom. It has turned out to be an effective way to address moral issues, discuss the limitations of science and think about facts and fiction in science (evaluate the integrity of information). It is important to realise in this recommendation that the clips we used in the module were selected in consultation with ethical researchers and that they were analysed by these ethical researchers. Not every fictional fragment will be equally suitable for science education. For this reason, we advocate the use of well-considered fictional 
clips as part of regular science lessons in order to introduce a dilemma, or discussion and reflection activity.

\section{Acknowledgements}

\section{References}

American Association for the Advancement of Science (1989). Science for all Americans. Project 2061. New York, Oxford University Press.

Biesboer, F. (2003). Genomics. Dreams, fears and fantasies. Public embedding of genomics research. The Hague, Netherlands Genomics Initiative.

Bolt, L.L.E., Verweij, M.F., \& Van Delden, J.J.M. (2005). Ethiek in de praktijk [Ethics in practice]. Assen, Koninklijke van Gorcum.

Driver, R., Newton, P., \& Osborne, J. (2000). Establishing the norms of scientific argumentation in the classroom, Science Education, 84, 287-312.

Erduran, S., Simon, S., \& Osborne, J. (2004). TAPping into argumentation: developments in the application of Toulmin's argument pattern for studying science discourse. Science Education, 88, 915-933.

Evans, J.H. (2002). Playing God? Human genetic engineering and the rationalization of public bioethical debate. Chicago, University of Chicago Press.

Fleming, R. (1986). Adolescent reasoning in socio-scientific issues. Part II: Nonsocial cognition. Journal of Research in Science Teaching, 23, 689-698.

Health Council of the Netherlands (2003). Public awareness about genetics. The Hague, Health Council of the Netherlands; publication no. 2003/05.

URL: http://mc.manuscriptcentral.com/tsed Email: editor_ijse@hotmail.co.uk 32 
Hogan, K. (2002). Small groups' ecological reasoning while making an environmental management decision. Journal of Research in Science Teaching, 39, 341-368.

Jiménez-Aleixandre, M., Rodríguez, A., \& Duschl, R. (2000). 'Doing the lesson’ or 'doing science': Argument in high school genetics. Science Education, 86, 314-342.

Keefer, M.W., \& Ashley, K.D. (2001). Case-based approaches to professional ethics: a systematic comparison of students' and ethicists' moral reasoning. Journal of Moral Education, 30, 377-398.

Keefer, M.W. (2003). Moral reasoning and case-based approaches to ethical instruction in science. In D.L. Zeidler (Ed.) The role of moral reasoning on socioscientific issues and discourse in science education (pp. 241-259). Dorderecht, Kluwer Academic Press.

Kennedy, D. (2006). Retraction of Hwang et al., Science 308 (5729) 1777-1783. Retraction of Hwang et al., Science 303 (5664) 1669-1674. Science, 311, 335.

Knippels, M.C.P.J. (2002). Coping with the abstract and complex nature of genetics in biology education. The yo-yo learning and teaching strategy. Utrecht, CD $\beta$-Press.

Knippels, M.C.P.J., Waarlo, A.J., \& Boersma, K.Th. (2005). Design criteria for learning and teaching genetics. Journal of Biological Education, 39, 108-112.

Kolstø, S. D. (2001a). Scientific literacy for citizenship: tools for dealing with the science dimension of controversial socioscientific issues. Science Education, 85, 291-310.

Kolstø, S. D. (2001b). 'To trust or not to trust, ...'- pupils' ways of judging information encountered in a socio-scientific issue. International Journal of Science Education, 23, 877-901.

Kortland, K. (1996). An STS case study about students' decision making on the waste issue. Science Education, 80, 673-673.

URL: http://mc.manuscriptcentral.com/tsed Email: editor_ijse@hotmail.co.uk 33 
Kortland, K. (2001). The problem posing approach to teaching decision making about the waste issue. Utrecht, $\mathrm{CD} \beta$ Press.

Leike, R.K. (1997). Experimental Design and the Analysis of Variance. Thousand Oaks, Sage and Pine Forge Press.

Levinson, R., \& Turner, S. (2001). Valuable lessons: Engaging with the social context of science in schools. London, Welcome Trust.

Lewis, J., Driver, R., Leach, J., \& Wood-Robinson, C. (1997). Working Paper 2: Understanding of basic genetics and DNA technology: the 'Young people's understanding of attitudes to, the new genetics' project. Leeds, CSSME.

Lewis, J., \& Leach, J. (2006). Discussion of socio-scientific issues: the role of science knowledge. International Journal of Science Education, 28, 1267-1287.

Means, M.L., \& Voss, J.F. (1996). Who reasons well? Two studies of informal reasoning among children of different grade, ability, and knowledge levels. Cognition and Instruction, 14, $139-178$.

Mepham, B. (2003). Ethics and animal farming. A web-based interactive exercise for students using the ethical matrix. Hampshire, Compassion in World Farming Trust (www.ethicalmatrix.nl).

Meulenberg, F., De Beaufort, I., \& Van de Vathorst, S. (2004). Frankenstein Revisited. Fiction and movies on cloning and the public debate. Journal for Humanistics, 18, 50-64.

Meulenberg, F., \& De Beaufort, I. (2006). Science, fiction, and science fiction. Overveen, Belvedère Publishers.

Millar, R., \& Osborne, J. (1998). Beyond 2000: Science education for the future. London, King's College London, School of Education.

URL: http://mc.manuscriptcentral.com/tsed Email: editor_ijse@hotmail.co.uk 34 
Minister of Education, Culture and Science (2004). National examination programme biology.

The Hague, Minister of Education, Culture and Science.

National Research Council (1996). National science education standards. Washington D.C., National Academy Press.

Oser, F. (1986). Moral education and values education: The discourse perspective. In M.C.

Wittrock (Ed.), Handbook of research on teaching (pp. 917-941). New York, MacMillan.

President's Council on Bioethics (2003). Being Human: Readings from the President's Council

on bioethics. Washington, D.C., The President's Council on Bioethics.

Ratcliffe, M. (1997). Pupil decision-making about socioscientific issues within the science curriculum. International Journal of Science Education, 19, 167-182.

Reiss, M.J. (1999). Teaching ethics in science. Studies in Science Education, 34, 115-140.

Russell, M., Marshall, E., Vogel, G., Sonneville, A., \& Kondro, W. (2001). U.K. cloning controversy, Science, 294, 1635.

Sadler, T. D., \& Zeidler, D. L. (2004a). The morality of socioscientific issues: Construal and resolution of genetic engineering dilemmas. Science Education, 88, 4-27.

Sadler, T. D. (2004b). Informal reasoning regarding socioscientific issues: a critical review of research. Journal of Research in Science Teaching, 41, 513-536.

Sadler, T. D., \& Zeidler, D. L. (2005a). The significance of content knowledge for informal reasoning regarding socioscientific issues: applying genetics knowledge to genetic engineering issues. Science Education, 89, 1-23.

Sadler, T. D., \& Zeidler, D. L. (2005b). Patterns of informal reasoning in the context of socioscientific decision making. Journal of Research in Science Teaching, 42, 112-138.

URL: http://mc.manuscriptcentral.com/tsed Email: editor_ijse@hotmail.co.uk 35 
Solomon, D., Watson, M., \& Battistich, VG. (2001). Teaching and Schooling effects on moral/prosocial development. In V. Richardson (Ed.) Handbook of research on Teaching (pp. 566-603). Washington D.C., American Educational Research Association.

Toulmin, S. (1958). The use of argument. Cambridge, Cambridge University Press.

Veugelers, W. (2000). Different ways of teaching values. Educational Review, 52, 37-46.

Waarlo, A.J. (2003). Acquiring genomics-related opinion-forming competence. Developmental research into a problem posing learning and teaching strategy. Paper presented at the $4^{\text {th }}$ ESERA conference Research and quality of science education, August 19-23, Noordwijkerhout, The Netherlands.

Young, E., \& Carrington, D. (2002). Cloning pregnancy claim prompts outrage. NewScientist, (http://www.newscientist.com/article.ns?id=dn2133).

Zeidler, D. L., Walker, K., Ackett, W. A., \& Simmons, M. L. (2002). Tangled up in views: Beliefs in the nature of science and responses to socioscientific dilemmas. Science Education, 86, 343-367.

Zohar, A., \& Nemet, F. (2002). Fostering students' knowledge and argumentation skills through dilemmas in human genetics. Journal of Research in Science Teaching, 39, 35-62.

URL: http://mc.manuscriptcentral.com/tsed Email: editor_ijse@hotmail.co.uk 36 


\section{Appendix 1}

\section{'Prenatal screening' dilemma}

Frank and Clair are a couple. They have wanted a child for years, and Clair is finally pregnant. During the pregnancy, they go for a check-up. Frank tells the physician about his father who recently passed away due to Huntington's disease. This is a lingering illness that gradually destroys brain cells and occurs later on in life (between the ages of 35 and 45). This fatal disease causes a growing decay that ends in total dependency.

The physician tells them that Huntington's disease is hereditary and is caused by a defect in a gene. Frank runs a 50\% risk that he inherited this defective gene from his father and may suffer from this illness in the near future. In addition, it is possible that he could pass on this defective gene to his children. Frank decides to do a DNA test, and it turns out that he indeed carries the defective gene.

This means that Frank and Clair's child also has a 50\% chance of carrying this defective gene. The only way to find this out is by means of an amniocentesis. What do they do if their child has this disease?

What is the dilemma confronting Frank and Clair?

What would you do? Describe your viewpoint as thoroughly as possible. Make use of the steps you described in exercise 1 . 
Table 1. Relation between learning activities (LA) per lesson (L), the five commonalities and the five phases and nine steps of Bolt et al. (2005)

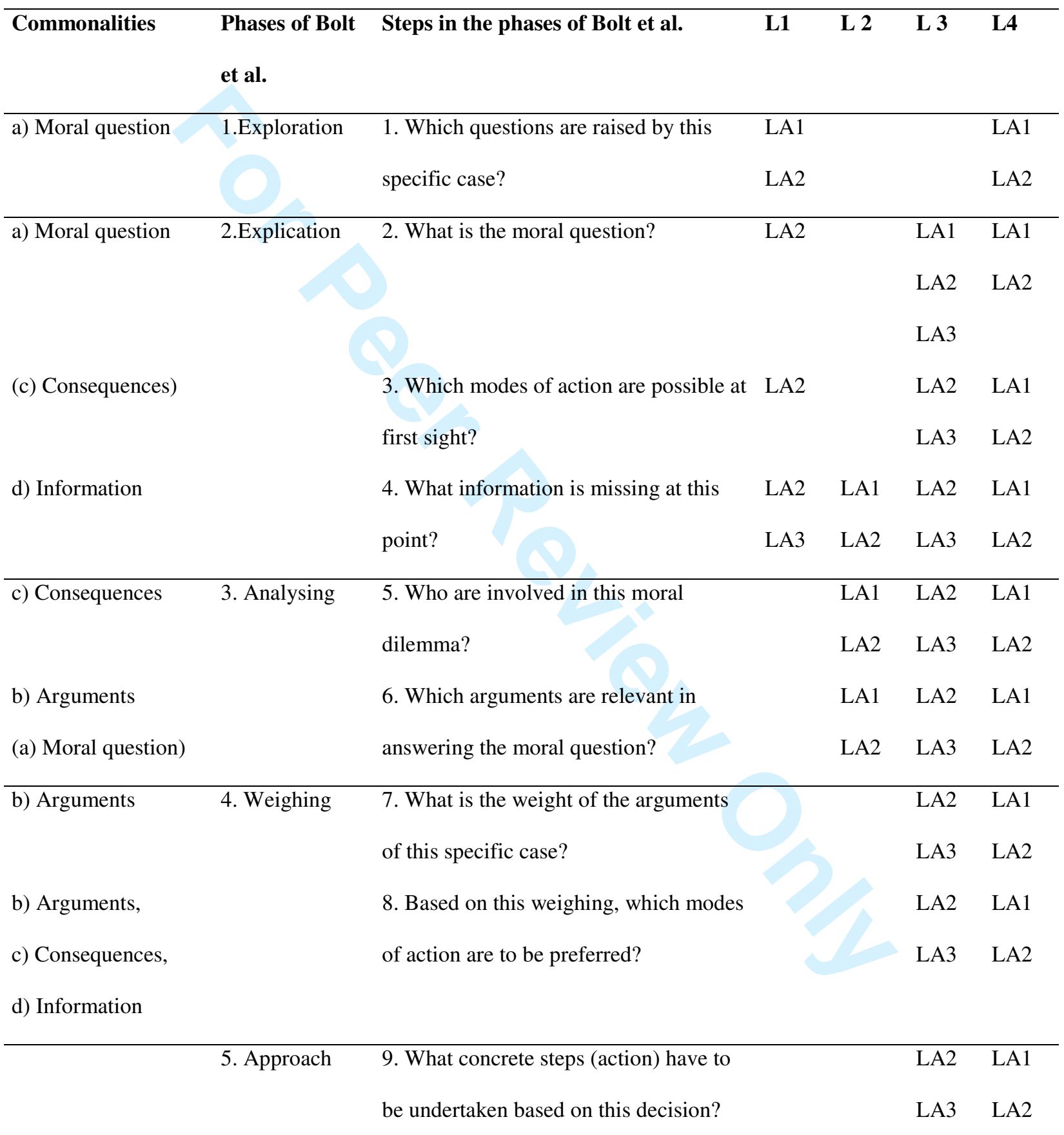

URL: http://mc.manuscriptcentral.com/tsed Email: editor_ijse@hotmail.co.uk 38 
1

2

3

4

5

6

7

8

9

10

11

12

13

14

15

16

17

18

19

20

21

22

23

24

25

26

27

28

29

30

31

32

33

34

35

36

37

38

39

40

41

42

43

44

45

46

47

48

49

50

51

52

53

54

55

56

57

58

59

60

Table 2. Experimental design and the numbers of students and classes per group

\begin{tabular}{lcccc}
\hline Group & Opinion-forming & Fiction & \multicolumn{2}{c}{ Number of students } \\
\hline Movie & + & + & 96 & (4 classes) \\
News report & + & - & 73 & (3 classes) \\
Control & - & - & 97 & $(4$ classes $)$ \\
\hline Total & & & & \\
\hline
\end{tabular}

URL: http://mc.manuscriptcentral.com/tsed Email: editor_ijse@hotmail.co.uk 39 
Table 3. Coding scheme of the four dependent variables

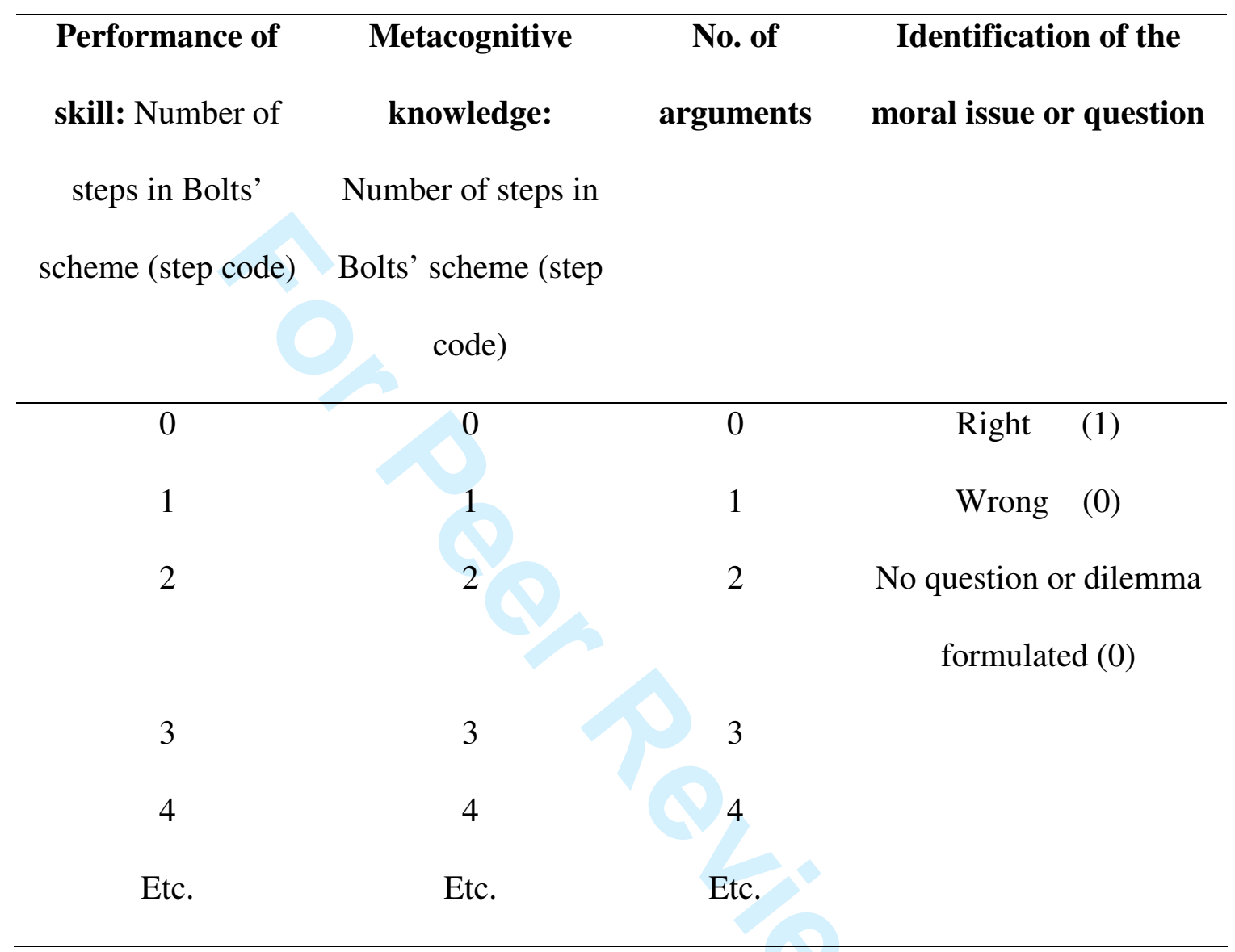


Table 4. Opinion-forming steps

\section{Steps/phases}

Step 1: Pose the moral question/dilemma.

Code 1

Step 2: Which choices can be made?

Code 2

Step 3: Which factual information is needed?

Code 3

Step 4: Who is involved?

Code 4

Step 5: Pro and con arguments are mentioned.

Code 5

Step 6: Pro and con arguments are weighted.

Code 6

Step 7: Weighing pro and con arguments against each other.

Code 7

Step 8: What are the consequences?

Code 8

Step 9: Opinion regarding, conclusion about or an answer to the moral Code 9 question is formulated.

URL: http://mc.manuscriptcentral.com/tsed Email: editor_ijse@hotmail.co.uk 41 
Table 5. Example of the coding of a students' written answer to the Huntington's disease dilemma. The coding of performance of skill by the number of steps in Bolts' scheme, number of arguments, and whether a correct moral question or issue has been formulated

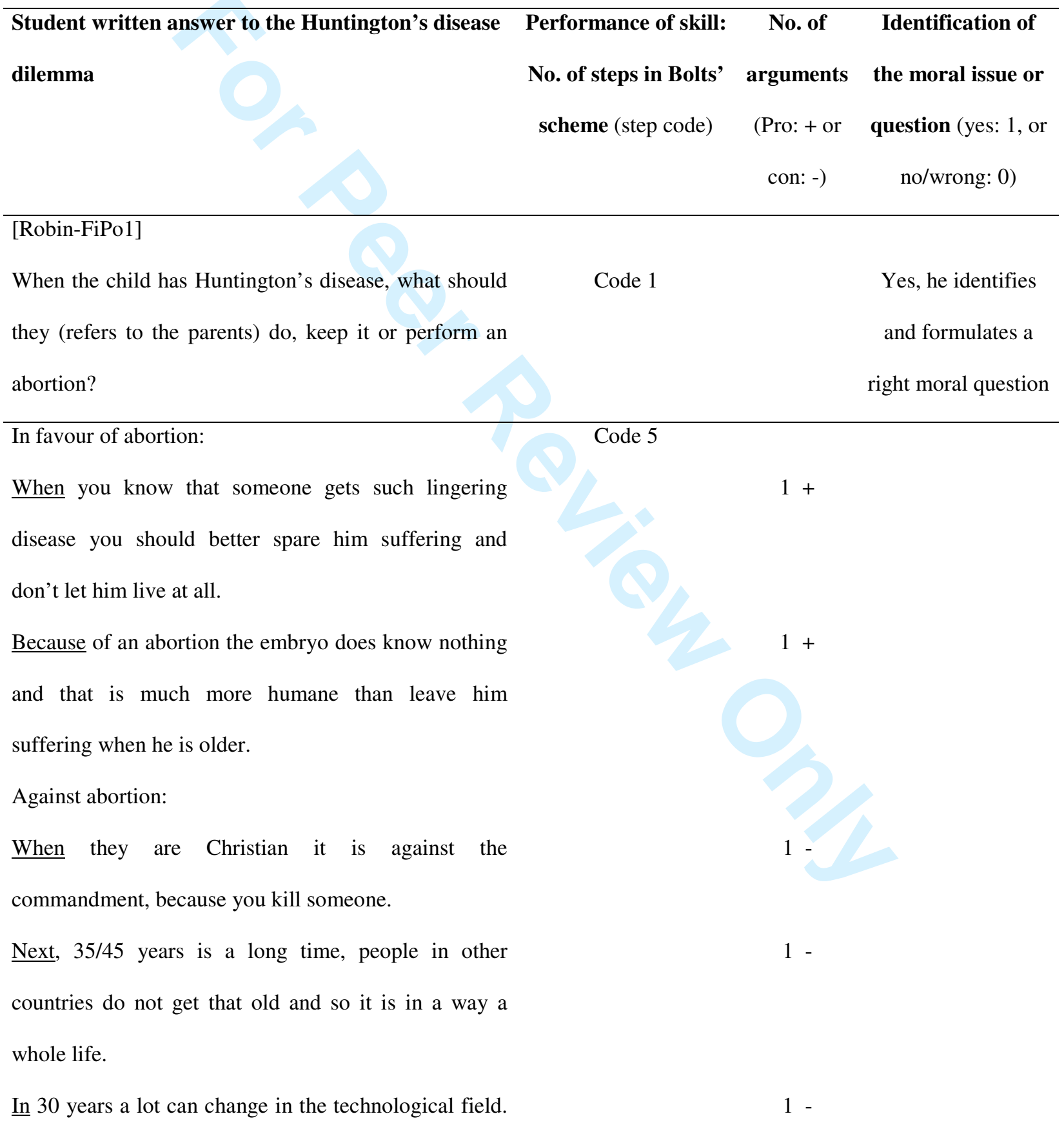

URL: http://mc.manuscriptcentral.com/tsed Email: editor_ijse@hotmail.co.uk 42 


\begin{tabular}{lcc} 
No. of steps is 5 & $\mathbf{5}$ & $\mathbf{1}$ \\
& $(3$ pro and & \\
2 con arg. $)$ & \\
\hline
\end{tabular}


Table 6. Example of the coding of metacognitive knowledge of a students' written answer

Student written answer to the question, which $\quad$ Metacognitive knowledge: Number of
steps they usually (should) take to arrive at their $\quad$ steps in Bolts'scheme (step code)
opinion about a dilemma

[Niels-Fi3]

Pre-test:

- Formulate the dilemma correct $\quad$ Code 1

- Search for pro and con arguments and weigh Code 5; Code 7

them against each other

\section{Number of steps is 3}

\section{Post-test:}

- Formulate the question $\quad$ Code 1

- Look for the possible answers $\quad$ Code 2

- Look up information about the subject Code 3

- Search for pro and con arguments and weigh Code 5; code 7

them against each other

- Give an answer/ take a viewpoint. Code 9

\section{Number of steps is 6}




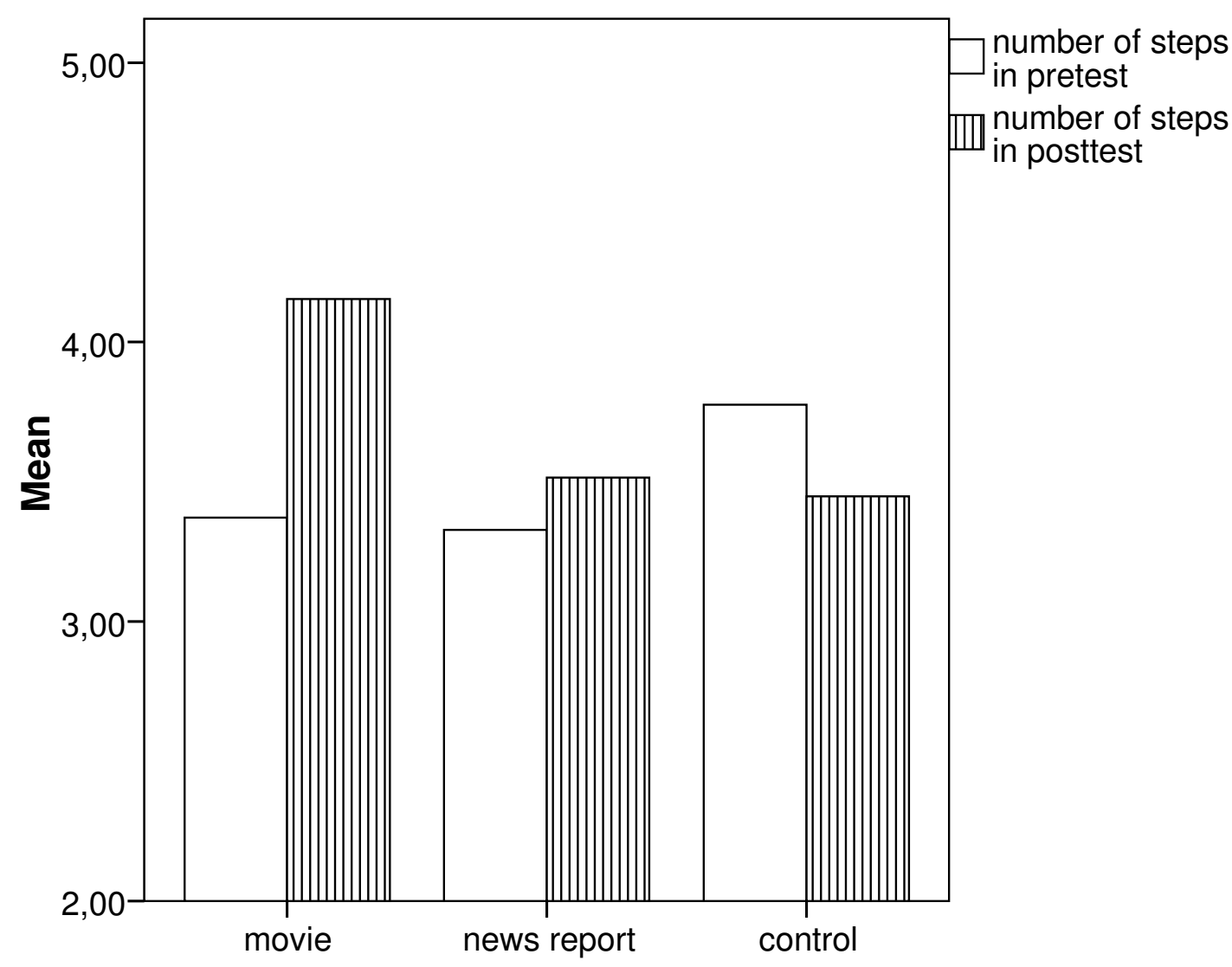

Figure 1. Average pre- and post-test scores for the three groups (performance test)

URL: http://mc.manuscriptcentral.com/tsed Email: editor_ijse@hotmail.co.uk 45 


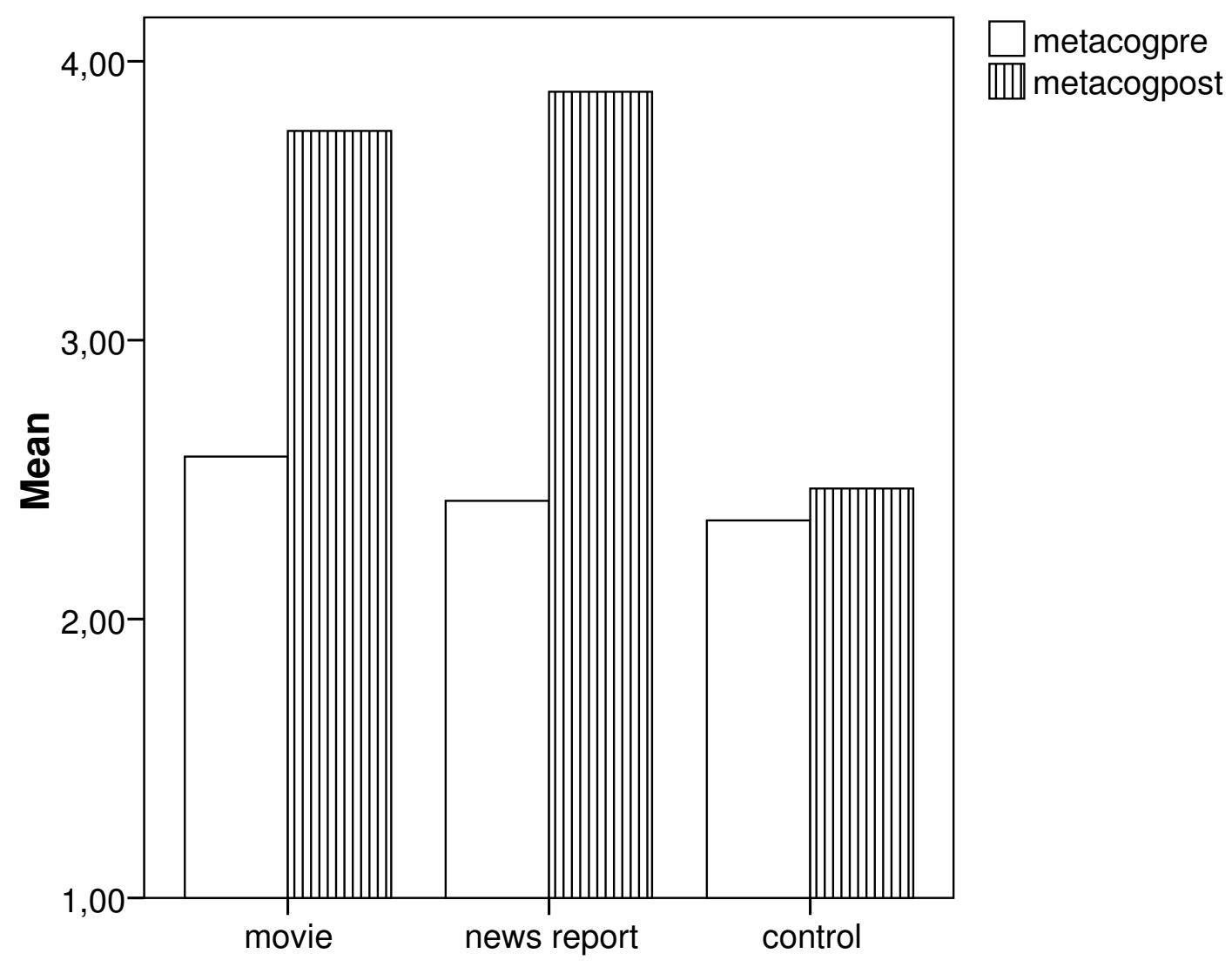

Figure 2. Average pre- and post-test scores for the three groups (metacognitive knowledge)

URL: http://mc.manuscriptcentral.com/tsed Email: editor_ijse@hotmail.co.uk 46 


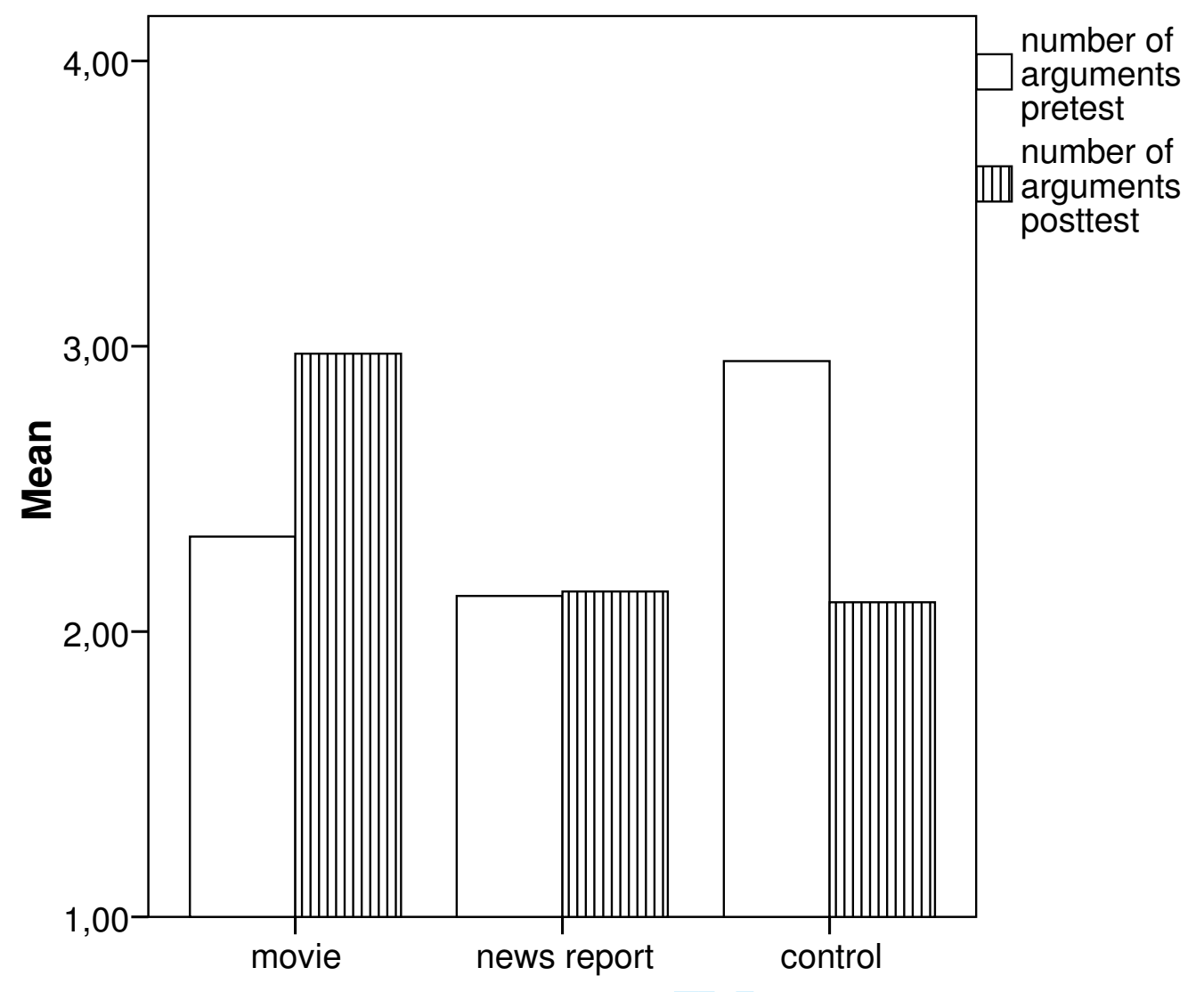

Figure 3. Average pre- and post-test scores for the three groups (number of arguments)

URL: http://mc.manuscriptcentral.com/tsed Email: editor_ijse@hotmail.co.uk 47 


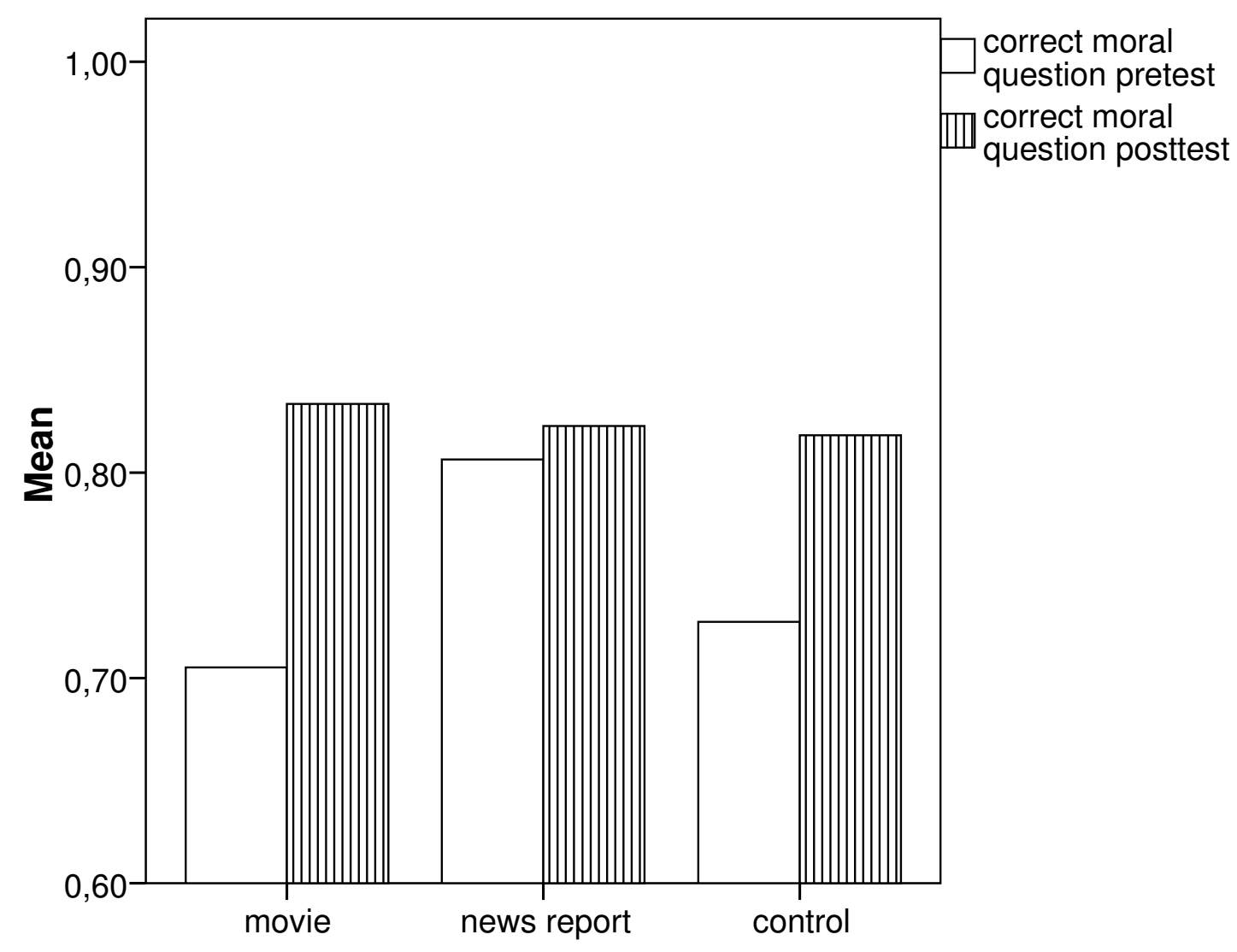

Figure 4. Average pre- and post-test scores for the three groups (extracting the moral dilemma)

URL: http://mc.manuscriptcentral.com/tsed Email: editor_ijse@hotmail.co.uk 48 